\title{
RETIREMENT VILLAGES AND RELATED CARE SERVICES: PERCEPTIONS, PREFERENCES AND NEEDS OF ELDERLY CONSUMERS AND PROVIDERS IN CAPE TOWN
}

\author{
CA Froneman, M.K.R. van Huyssteen, IJ van der Merwe \\ University of Stellenbosch
}

\begin{abstract}
This article describes the findings of a study in the Cape Metropolitan Area and its fringe districts of the perceptions, preferences and needs of elderly persons and the views of housing providers for the elderly regarding retirement housing and related care services. Interviews were conducted with 228 sampled elderly persons in neighbourhoods with a high concentration of the elderly and in selected retirement villages in the study area. The views of experts on retirement housing and role players in the field of elderly care were elicited separately. The basic preferences of the elderly can be summarized as: renting residential units instead of buying them; no luxuries such as therapy services; safety considerations incorporated in the design of the interior of the units; being able to use their own furniture in the units; primary health care offered; availability of recreational facilities; good corporate management; and accessibility to essential general services (in terms of the location of the village). These findings are considered for consumers in different cultural and socio-economic groups and are also compared with the views of developers, housing providers and other role players. It is contended that - given the Government's new policy on housing and care for the elderly - the findings may assist the providers of retirement housing and related care services to understand the diversity of needs of the South African mature retirement market and to provide facilities and services accordingly.
\end{abstract}

\section{INTRODUCTION}

Recent legislation has created a new situation in the field of housing for the aged in South Africa. This article deals with some aspects of a possible future role for retirement villages within the new dispensation. The views, perceptions, preferences and needs of two samples of elderly respondents served as the principal data source in this respect.

\subsection{Housing the elderly in South Africa: Changing the ground-rules}

Since the 1980s the provision of housing for the aged in South Africa has been regarded as a joint venture of the public and the private sectors. However, the new social welfare policy introduced by the Department of Welfare and Population Development in 1997 (South Africa, 1997) proposed the phasing out of all state-funded homes for the elderly by the year 2000 and the conversion of all such existing facilities into homes for the exclusive use of frail individuals of all race groups who are in need of 24-hour nursing care. This population type (in state-funded frail homes) should not exceed $2 \%$ of the total elderly population. The Department has offered no suggestions regarding the provision of alternative housing for non-frail elderly persons with limited financial resources who could previously be accommodated in these facilities.

Clearly the new policy of the Department has changed the ground-rules in the field of housing for the elderly in South Africa. An obvious implication is that the private sector (N.G.O.'s, churches, developers and others) will in future have to provide housing for an increased proportion of the 
aged population - i.e. for all those non-frail senior citizens of all race and income groups who are either not willing or able to live with their children or other relatives or friends, and/or not willing or able to afford living independently on their own (e.g. in privately rented accommodation or in a house of flat of their own).

This situation raises a number of important research questions.

Firstly, how large is the housing market for non-frail elderly individuals, and how rapidly can it be expected to expand in future?

Secondly, what proportion of the non-frail elderly housing market is currently - and will in future be - dependent on purpose-built housing for the aged, being unable or unwilling to live independently on their own and/or to find accommodation with family or friends.

Thirdly, who should provide the housing for this section of the elderly group, and what is the expected role of these role players in the provision of housing for such a broad elderly market, most of whom have only limited financial resources but varied social needs?

Fourthly, what type(s) of housing options should be provided?

Fifthly, given the diversity of the South African population, what is the nature of the submarkets within the broad non-frail, non-dependent and/or non-family reliant elderly housing market, and how can this differentiation be expected to impact on the provision of housing for this large elderly group?

Finally, what are the views, perceptions, needs and preferences of the elderly themselves regarding the various possible housing options, and are these differences absorbed in the various submarkets and/or between those currently living in different housing environments?

The foregoing questions make it clear that much research and innovative thinking will be required if we are to ensure that the growing number of elderly people in our population are to be properly housed in future. Additionally, it should of course be remembered that the elderly housing market is by definition different in certain respects from that for the younger age cohorts. The principal difference arises from the fact that many of the aged (even those currently in the non-frail category) require, or will at some future stage require, some form of care. Hence the provision of care facilities, the level at which it is to be provided, and the views, perceptions, needs and preferences of the elderly themselves in this regard ought to be an integral consideration in the housing solution and proposals which is envisaged.

Another feature of the elderly housing market is the fact that elderly persons typically resist change in their lives and their environment and may be expected to object against relocation to another housing facility - especially one that does not meet their expectations. Elderly persons also value their independence and often do not want to make adjustments in their housing and care situations that will reduce that independence (Lumpkin, Gibler \& Moschis, 1992).

\subsection{A new role for retirement villages?}

The foregoing are very broad considerations which feature mainly as background to the research reported here. This research (Froneman, 2004) had a much narrower focus, concentrating as it did on the potential contribution of but one of several possible "solutions" to strategies relevant to the problem of housing provision for the elderly in future. The housing "solution" in question is that of the so-called "retirement village". 
According to the South African Property Owners' Association (SAPOA, 1993) a retirement village can be defined as a building or buildings together with the land upon which it is situated, designed or used for the housing of people in excess of a certain age, which would normally have related uses such as recreation, health care, social and catering facilities. It should be added that retirement villages presently cater almost exclusively for but a single elderly group, i.e. those that are both relatively wealthy and white. This is only a small percentage of the total elderly population in South Africa, and may in fact be described as a mere niche market. However, in view of the changed circumstances in the elderly housing market, the question arises - and this was a principal focus in the research - whether in future retirement villages might not be capable of providing housing for a greater percentage of elderly people than at present.

In investigating this matter, much attention was given to the views, perceptions, preferences and needs of the elderly themselves regarding the suitability of retirement villages as a housing option for the elderly. The underlying rationale is that such knowledge may assist in identifying and eliminating possible shortcomings in the retirement village concept as currently applied, thus hopefully broadening its appeal to a wider segment of the elderly population.

Furthermore, in view of the importance of care facilities and the fact that existing retirement villages show considerable variation (Froneman, 2004), it was important to look also at the related care services and at the views, perceptions, etc. of the elderly in this regard.

The research investigating these matters was set in Cape Town and its fringe districts. Section 3 gives the relevant details, whilst subsequent sections set out some of the principal findings. However, before these aspects can be presented, an attempt must first be made to give a general indication of the extent and nature of the expected future demand for retirement housing and the related care services.

\section{FUTURE DEMAND FOR RETIREMENT HOUSING IN SOUTH AFRICA}

\subsection{Market growth}

As the size of the South African elderly population expands the demand for retirement housing and related care services, e.g. home care and frail-care, can be expected to increase. However, to serve this increasing demand effectively, the developers and providers of housing and related care services to this population group also need to understand the preferences and needs of consumers. More specifically, they need to recognise that within the elderly population there are distinguishable market segments, which translate into differential needs, preferences and affordability levels. An important objective of the research was therefore to identify possible market segments which exist among the elderly in Cape Town and its fringe districts (see Section 2.3), to analyse their diverse housing and related care needs and preferences, and to compare their perceptions, needs and preferences with the opinions of housing providers and other role players in the field of housing and care for the aged.

According to Statistics South Africa (1996) and the demographic model of ASSA 2000 (2003) there will be an average increase of 50271 elderly people yearly from 1996 to 2005, and 122947 yearly from 2005 to 2015 . This increase in the size of the South African elderly population is due to the fact that at present more South Africans are reaching retirement age and generally have a greater life expectancy. The total number of elderly persons will increase from 3257443 in 2005 to 4486918 in 2015. By 2035, according to Hofmeyr, Mostert and Oosthuizen (1997), the total number of elderly persons will be 6321000 . Furthermore, they project that in $201066 \%$ of the elderly population will be blacks, $23 \%$ whites, $8 \%$ coloureds and $3 \%$ Asians. The size of the black 
elderly population within the total elderly group will increase at a disproportionate rate. However, since whites enjoy a greater life expectancy than blacks, coloureds and Asians - a gap of 10 years between whites and blacks - the number of "very old" whites will continue to be substantial.

\subsection{Market differentiation}

South Africa's elderly population is not homogeneous in terms of age, culture or socio-economic class and therefore submarkets exist within the housing market for this group. The most important distinguishing characteristics of these submarkets are in terms of age and income/race group; in South Africa, for historical reasons, income groups and race/cultural groups largely coincide with each other and will therefore be treated as a single category.

\subsubsection{Age groups}

Gerontologists classify elderly persons into three age groups: the "young-old" (60-69 years), the "old-old" (70-79 years) and the "very old" (80 years and over) (Cluff, 1993). World-wide, the "very old" age group is growing at a disproportionate rate. While persons in the younger elderly age groups may be expected to enjoy good health and to be able to live independently, those in the older group may be expected to suffer increasingly physical and cognitive impairment and therefore to become less active and more frail. As a result they are less able to live independently than persons in the younger elderly groups and thus to become increasingly dependent on others for care. However, while those in the younger groups may find it easier to live independently, they still need to make choices regarding retirement housing. An understanding of the housing and related care needs and preferences of persons in the different age segments is essential for future planning.

\subsubsection{Income/race groups}

The legacy of apartheid has created deep socio-economic divisions between the race groups in South African society. This has led to a diversity of lifestyles and levels of affordability that must be taken into account in an analysis of retirement housing preferences and market opportunities.

According to Van den Berg (1996), the pre-social pension income of elderly person in South Africa is very low for the great majority of them. Thus in 1996 the mean monthly income for the total elderly population was a mere R259 per person. The vast majority of elderly South Africans therefore qualify for the non-contributory, means-tested social old-age pension - an amount of R490 a month in July 1998 (R640 in 2003). However, due to large income differences amongst the main ethnic groups, take-up rates of the social pension differ substantially amongst them. Thus in 1996 the mean (before social pension) of elderly persons in the different race groups were R54 for blacks, R133 for coloureds, R251 for Asians and R1 414 for whites per month. Only amongst whites did more than a quarter have a per capita income exceeding R75 per month (R900 per annum), with almost $30 \%$ earning more than R2 000 per elderly person per month. Hence, the take-up rate of the pension amongst whites was a mere $20 \%$, as against $90 \%$ in the case of blacks, $85 \%$ in the case of coloureds and 62\% in the case of Asians (Van den Berg, 1998). The great majority of elderly blacks, in particular, are thus almost entirely dependent on a social pension as their only income. In this regard it should be remembered that, until fairly recently, private provision for retirement amongst persons other than whites was usually lacking since occupational retirement insurance funds had largely excluded previous generations of black workers.

The submarkets identified in this section were subsequently taken into account in the research design for the Cape Town study. A brief discussion of the latter follows. 


\section{RESEARCH DESIGN AND DATA COLLECTION}

A study aimed at finding answers to the questions outlined thus far was conducted in Cape Town and the fringe districts of the Cape Metropolitan Area in 1997. A total of 228 persons aged 60 years and over were interviewed during two stratified sample surveys and asked to answer "yes" or "no" to a series of questions on whether they regarded particular aspects related to retirement villages and care facilities important. In the first survey a total of 109 senior citizens were sampled in nine neighbourhoods spread across the various racial and socio-economic subgroups in the metropolitan area; the respondents comprised 42 blacks, 34 coloured and 33 white persons also stratified by elderly age group. The study included the suburbs of Lavender Hill, Langa, Khayelithsa, Gugulethu, Silvertown, Goodwood, Kensington, Constantia and Ruyterwacht (Figure 1).

FIGURE 1

\section{SAMPLED NEIGHBOURHOODS}



The second survey was conducted in ten selected retirement villages, in which a total of 119 residents (again stratified by elderly age group) were sampled using a voluntary sample method. The selected retirement villages - representing a $29.4 \%$ random sample of 34 villages in the study area in 1997 - are situated in the areas of Parow, Durbanville, Stellenbosch, Somerset-West, Pinelands, Tokai and Hout Bay (Figure 2).

In addition to the two surveys amongst elderly respondents, the views of 36 role players in the field of elderly housing and care were solicited through personal interviews and a mail survey. Apart from housing providers, this sample also included gerontologists, sociologists, government officials and managers of retirement villages. 
FIGURE 2

SAMPLED RETIREMENT VILLAGES

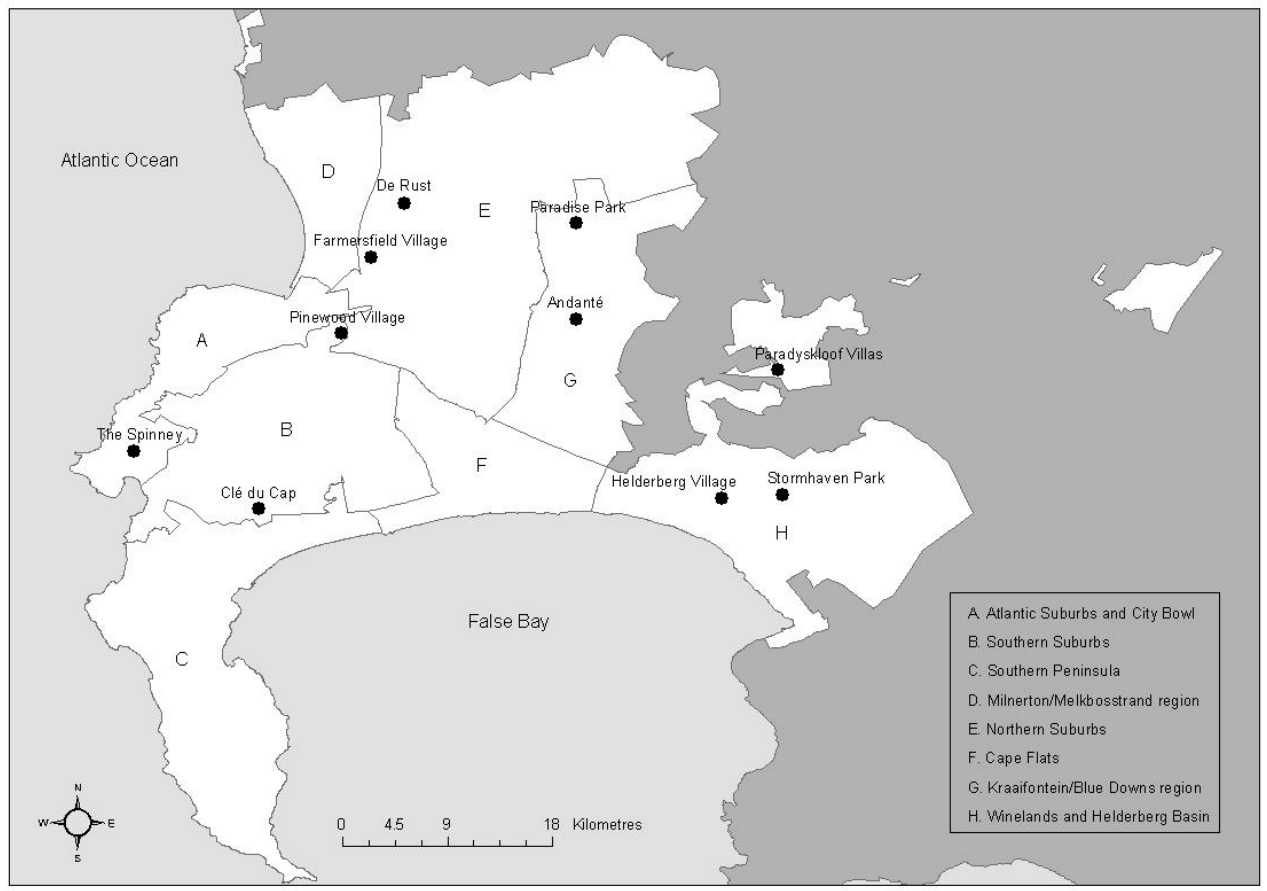

The data was satatistically and qualitatively processed (Table 1 and 2). The following sections present some of the findings which were derived. These related in the first place to the views and perceptions of the two samples of elderly persons regarding retirement housing, frail-care facilities and home care. Where indicated, secondly, the findings are also compared with the opinions of the developers, housing providers and other role players. Section 4 focusses on the findings relating to housing preferences and Section 5 on those relating to perceptions regarding frail-care facilities and home care.

\section{RETIREMENT HOUSING PREFERENCES}

The preferred characteristics of a retirement village are shown separately for the different samples in Table 1 (only characteristics higher than fifty percent were included). The following discussion first compares the preferences of the neighbourhood and retirement village samples (Samples 1 and 2). It then looks at the preferences by income group and by age group (Samples 1 and 2 considered together in both instances), compares the preferences of the three cultural/race groups represented in the neighbourhood sample (Sample 1), and finally examines the views of the developers and other role players in the this regard (Sample 3). 
TABLE 1

PREFERRED CHARACTERISTICS OF RETIREMENT HOUSING FACILITIES FOR THE DIFFERENT SAMPLES: PERCENTAGES OF "YES"

\begin{tabular}{|c|c|c|c|c|}
\hline & \multirow{2}{*}{$\begin{array}{c}\text { Total of } \\
\text { samples } \\
1 \& 2\end{array}$} & \multirow{2}{*}{$\begin{array}{c}\text { Sample 1 } \\
\text { Community- } \\
\text { dwelling }\end{array}$} & \multirow{2}{*}{$\begin{array}{c}\text { Sample 2 } \\
\text { Retirement } \\
\text { village }\end{array}$} & \multirow{2}{*}{$\begin{array}{c}\text { Sample } 3 \\
\text { Role players }\end{array}$} \\
\hline & & & & \\
\hline $\mathbf{N}$ & 228 & 109 & 119 & 36 \\
\hline Reasonable monthly levy & 50 & 42 & 59 & 72 \\
\hline Purchase option & 51 & 24 & 77 & 31 \\
\hline Private kitchens & 66 & 56 & 76 & 34 \\
\hline Safety features & 87 & 95 & 78 & 75 \\
\hline Size of rooms & 62 & 52 & 72 & 47 \\
\hline Use own furniture & 56 & 38 & 75 & 63 \\
\hline Caring environment & 64 & 82 & 47 & 66 \\
\hline Therapy services & 59 & 81 & 37 & 34 \\
\hline $\begin{array}{l}\text { Acceptance of medical } \\
\text { insurance }\end{array}$ & 59 & 57 & 60 & 38 \\
\hline $\begin{array}{l}\text { Programmes to foster } \\
\text { independence }\end{array}$ & 57 & 73 & 40 & 53 \\
\hline Multiple levels of care & 74 & 78 & 71 & 50 \\
\hline Primary health care & 79 & 83 & 74 & 59 \\
\hline Religious affiliation & 52 & 68 & 35 & 38 \\
\hline Organised activities & 56 & 58 & 55 & 38 \\
\hline Recreation & 61 & 59 & 62 & 47 \\
\hline Companionship & 71 & 78 & 65 & 63 \\
\hline Meals & 59 & 87 & 30 & 56 \\
\hline Quality of food & 64 & 91 & 37 & 63 \\
\hline $\begin{array}{l}\text { Good commmunication with } \\
\text { management }\end{array}$ & 73 & 81 & 66 & 72 \\
\hline Close to family & 60 & 78 & 42 & 47 \\
\hline Close to hospital & 71 & 88 & 54 & 56 \\
\hline Close to shopping facilities & 65 & 63 & 67 & 50 \\
\hline Close to recreation activities & 57 & 57 & 58 & 47 \\
\hline Location & 59 & 58 & 59 & 56 \\
\hline
\end{tabular}


TABLE 2

PERCEPTIONS REGARDING HOME CARE AND FRAIL CARE FOR THE DIFFERENT SAMPLES: PERCENTAGES OF "YES"

\begin{tabular}{|c|c|c|c|c|}
\hline & \multirow{2}{*}{$\begin{array}{c}\text { Total of } \\
\text { samples } \\
1 \& 2\end{array}$} & \multirow{2}{*}{$\begin{array}{l}\text { Sample } 1 \\
\text { Community } \\
\text { dwelling }\end{array}$} & \multirow{2}{*}{$\begin{array}{c}\text { Sample 2 } \\
\text { Retirement } \\
\text { village }\end{array}$} & Sample 3 \\
\hline & & & & Role players \\
\hline $\mathbf{N}$ & 228 & 109 & 119 & 36 \\
\hline Home care & 62 & 55 & 68 & 48 \\
\hline Unfair on family & 55 & 40 & 70 & 28 \\
\hline Does not want to be a burden & 91 & 94 & 87 & 72 \\
\hline $\begin{array}{l}\text { Living with children jeopardize } \\
\text { relationship }\end{array}$ & 53 & 32 & 74 & 50 \\
\hline Will preserve my dignity & 65 & 69 & 60 & 47 \\
\hline $\begin{array}{l}\text { Different generations do not } \\
\text { mix well }\end{array}$ & 54 & 42 & 65 & 38 \\
\hline $\begin{array}{l}\text { Children's right to } \\
\text { independence }\end{array}$ & 91 & 91 & 90 & 69 \\
\hline Not right to live with children & 66 & 48 & 83 & 58 \\
\hline Sharing of home & 58 & 67 & 48 & 38 \\
\hline Too expensive & 50 & 62 & 37 & 44 \\
\hline No-one to share & 69 & 80 & 57 & 34 \\
\hline No caring person to share & 55 & 58 & 52 & 34 \\
\hline Frail Care Homes & 52 & 50 & 53 & 51 \\
\hline $\begin{array}{l}\text { Want to live with people of own } \\
\text { age }\end{array}$ & 53 & 40 & 65 & 69 \\
\hline $\begin{array}{l}\text { Security of knowing will be } \\
\text { cared for }\end{array}$ & 89 & 93 & 84 & 75 \\
\hline Not ready for home yet & 86 & 86 & 86 & 69 \\
\hline Homes make one feel old & 60 & 55 & 65 & 60 \\
\hline Homes are a last resort & 73 & 76 & 69 & 56 \\
\hline Once enter a home, never leave & 54 & 59 & 48 & 53 \\
\hline Homes are not all alike & 58 & 48 & 68 & 63 \\
\hline
\end{tabular}

\subsection{Samples 1 and 2 compared}

The respondents who lived in the community and those who lived in a retirement village were found to have six strong preferences or requirements regarding retirement housing in common: safety features inside the residential units (95\% and 78\% "yes" responses respectively), multiple levels of care $(78 \%$ and $71 \%)$, the availability of primary health care at the facility $(83 \%$ and $74 \%$ ), companionship (78\% and 65\%), good communication between management and residents (81\% and 66\%), and proximity to shopping facilities $(63 \%$ and $67 \%)$. Despite these shared preferences, there was however also many indications that the two groups have different ideas 
about what a retirement facility should offer consumers. Thus the community-dwelling respondents attach great importance to certain aspects which a majority of those in the retirement villages do not consider all that significant. This includes matters such as the presence or availability of a caring environment ( $82 \%$ vs $47 \%)$, therapy services ( $81 \%$ vs $37 \%)$, programmes to foster independence ( $73 \%$ vs $40 \%)$; affiliation with a particular religion $(68 \%$ vs $35 \%)$; the availability of meals ( $87 \%$ vs $30 \%)$ and the quality of food (91\% vs $36 \%)$; location close to their family (78\% vs $42 \%$ ) and to a hospital ( $88 \%$ vs $54 \%$ ); and the option to rent a unit rather than to buy one (more than $69 \%$ of this group would prefer renting rather than ownership, vs more than two thirds of those already in the retirement village who preferred the option to purchase rather than renting).

Apart from the latter aspect, the respondents in retirement villages also felt much more strongly than the community group about certain physical or design features, such as the availability of private kitchens ( $76 \%$ vs $52 \%$ ), the size of the rooms ( $72 \%$ vs $52 \%$ ), the option to use their own furniture (75\% vs $38 \%)$, as well as the availability of club facilities (57\% vs $41 \%)$.

In considering the foregoing contrasts between the two groups of respondents, it should be borne in mind that almost all of those who lived in a retirement village were in the middle to high income categories, while most of those in the community were in the low income category. At the time of the survey, the majority for the community-dwelling respondents still lived with their children. However, it was foreseen that circumstances might change, which would force the elderly persons to move to alternative accommodation. Income was found to be the strongest predictor of whether a person would be interested to live in independent retirement housing or not.

\subsection{Preferences by income group}

In view of the close correspondence between the retirement village sample and high-income respondents, versus mainly low-income respondents in the community sample, it was to be expected that a comparison between the preferences of high and low income respondents would yield virtually a mirror image of the results discussed in section 4.1. This can be confirmed by inspecting the relevant figures in Table 1. These relate to aspects such as ownership and purchase option; own furniture use, safety, room size and private kitchen; caring environment; availability of therapy services, multiple care levels and primary health care; religious affiliation, companionship, meals, food quality and the availability of club facilities; and also good communications with management and proximity of family and hospitals.

A separate analysis of the preferences of the small group of high-income respondents who lived in the community showed that these correlated with those of the respondents in the retirement villages. This finding appears to confirm that there is a direct relationship between the financial capacity of elderly persons and the kind of features which they regard as important in a retirement housing facility. The much higher yes-percentage regarding the importance of a reasonable levy in the case of the entire high income group than in that of the retirement village sample on its own ( $74 \%$ vs $59 \%$ ) is probably due to the inclusion of the high-income community respondents in the case of the former figure and their exclusion in the case of the latter.

\subsection{Preferences by age group}

Examination of the "yes"-percentages in Table 1 shows that four preferences are strongly shared by all three age groups: safety features (all three percentages between $81 \%$ and $95 \%$ ), availability of multiple levels of and of primary health care (74\%-75\% and 74\%-86\% respectively), and good communications with management $(72-75 \%)$. These were also the strongest shared preferences of the two samples as a whole (section 4.1), and appear to be the minimum requirements ascribed to 
by the great majority of respondents, regardless of present housing environment, age or income group.

In four other cases the importance level assigned by the three age groups - through mostly much lower - shows a clear rise between the lowest and highest age categories. This more or less accords with expectations (Strydom \& Rip, 1988). Thus declining financial capacity with increased age leads to more concern with money matters such as the levy and the rent (57\% vs $48 \%$ and $49 \%$ vs $34 \%$ for the oldest and youngest groups respectively). Similarly, the greater importance attached to the use of own furniture (74\% vs $47 \%$ ) and to communal eating arrangements (49\% vs $41 \%$ ) appears to result from an increased desire with increasing age to be in familiar surroundings and to share the company of others at mealtimes.

Beyond mealtimes, however, the desire for companionship unexpectedly drops with increased age ( $80 \%$ importance level in the youngest age group vs $63 \%$ in the oldest). Inverse relationships that were equally unexpected included the decrease (with age) of the importance assigned to a caring environment (a decline from $70 \%$ in the youngest group to $60 \%$ in the oldest), acceptance of medical insurance ( $63 \%$ to $51 \%$ ), religious affiliation (55\% to $51 \%$ ), availability of meals $(67 \%$ to $54 \%)$ and proximity of a hospital $(75 \%$ to $66 \%)$. It is not known what the reasons are for these unexpected findings.

Three other inverse relationships were more in line with expectations (Strydom \& Rip, 1988). Thus there is a decreasing concern with ownership as age increases (51\% to $40 \%)$, as also with the availability of organized activities and recreation opportunities (62\% to $49 \%$ and $63 \%$ to $57 \%$ respectively).

\subsection{Preferences by cultural (race/ethnic) group}

Differential preferences regarding retirement housing were found within the different cultural groups. Black respondents wanted a safe environment $(93 \%)$ and placed an emphasis on the provision of meals $(86 \%)$, the quality of the food $(95 \%)$, the availability of health care $(71 \%)$, the availability of therapy $(76 \%)$, and the proximity of the facility to a hospital (74\%) and to family $(83 \%)$. For white respondents it was important that there be good communication between the management of the facility and the residents (94\%), programmes to encourage or support independence $(78 \%)$, and recreation facilities $(81 \%)$. Coloured respondents indicated a strong preference for the availability of therapy $(100 \%)$, and the proximity of the residential facility to shopping facilities $(81 \%)$ and recreation areas $(72 \%)$. The geographical location of the facility within the city (94\%) was also important to them and they would value the quality of the food $(88 \%)$.

\subsection{Views of developers and other role players}

The preferences of the developers and other role players regarding a retirement village focused on the management concerns of a retirement village. Like most of the aged samples, they were first of all also concerned about the safety features of the facility (75\%) followed by a reasonable levy per month as well as good communication between management and the residents (72\%). They were also (to a lesser extent) concerned about a caring environment (66\%), the use of own furniture in the units (63\%), companionship (63\%) and the quality of the food (63\%). 


\subsection{PERCEPTIONS OF FRAIL-CARE FACILITIES, HOME CARE AND SHARING OF HOME}

\subsection{Introduction: Caring for the elderly}

When growing older, people become frail and the need arises for them to receive health care and related support services. The frail elderly have three choices: to remain in their homes and receive home care services, or being cared for in a frail-care facility, or home-sharing. A frail-care facility is usually either in a retirement village (for the more affluent elderly) or in a home for the elderly (for the low-income elderly).

\subsection{Perceptions of frail-care facilities}

The transformation of "old age homes" in post-apartheid South Africa has brought about new expectations and perceptions. The conversion of traditional homes for the elderly into frail-care homes has created the concept of a home for frail old people of all races who are in need of 24hour nursing care and who depend on a social pension. On the other hand a frail-care unit traditionally refers to a private unit which is operated $s$ a free enterprise. Such a facility is either attached to a retirement village or - less frequently - is freestanding. While persons belonging to the low-income category may therefore refer to a frail-care facility as a "frail home", more affluent persons may refer to such a facility as a "frail-care unit". The operation of frail-care facilities has become one of the most costly services in the provision of care to the elderly population. According to Loubser (1993) the establishment of such a facility should be approached with an open mind. He has pointed out that only a maximum of $5 \%$ of elderly persons will ever need frail care and that it is only viable to run a frail-care unit which has a minimum of 50 beds. Thus, to operate a unit of 50 beds, a population of at least 1000 elderly persons are needed. For a frail-care unit to be economically viable. Ferreira (1996) suggests that it is most practical for the unit to serve multiple retirement facilities, although this may not be acceptable to persons who may not want to leave their retirement village to enter such a facility when they need this type of care.

Table 2 reveals differences as well as similarities between the two groups of elderly respondents regarding their perceptions of frail-care facilities. Only features with percentages higher than fifty percent were included in the table. With regard to the differences, the community-dwelling respondents had a largely negative perception of such facilities, as is evident in their affirmative responses to the following statements: "Frail care homes are a last resort" (76\% "yes" response); "Once you enter a frail-care home you never leave" (59\%); "Homes have a bad reputation" (58\%); and "Moving to a frail-care home will make me feel old" (55\%). Also, only $29 \%$ were of the opinion that such homes have improved in recent years. Nevertheless, $22 \%$ of the respondents were of the opinion that they would need to enter a frail-care facility within the coming five years.

The respondents who lived in a retirement village had different opinions in some respects and appeared to be more informed about frail-care units. Thus more of them (68\% vs $48 \%)$ perceived that frail-care units are not all alike and that they have improved in recent years (43\% vs 29\%). Moreover, fewer of them agreed that such units are a last resort (69\% vs 76\%), that you never leave them once entered (only 48\%) and that they have a bad reputation (only 24\%). This may explain why $58 \%$ (vs only 18\%) expected to go to a frail home in the next 5 years.

Despite these differences, the respondents in both samples agreed generally that a frail-care facility should be attached to a retirement home (78\% and 70\% of Samples 1 and 2 respectively), but that admission to such a unit would make them feel old (55\% and 65\%). Further, a strong majority in each group shared the following perceptions: They were not yet ready to enter a frail 
care home ( $86 \%$ in both samples), since they regarded it to be a place without dignity $(66 \%$ in both). However, although they did not expect to spend their old age in a frail care facility $(78 \%$ and $67 \%)$, they would enter one if they desperately need to do so (93\% and $84 \%$ ).

Close inspection of Table 2 show remarkably similar perceptions amongst the various age and income groups, although the youngest and lowest income groups were slightly more negative than the others about the reputation of frail-care homes and more certain that one doesn't leave them once entered. Very few (only 22\%) low-income respondents could foresee that they might have to.

Amongst the three cultural/race groups in the neighbourhood sample, black respondents had particularly strong negative perceptions of frail-care facilities. The vast majority perceived that these facilities had not improved in recent years (88\%), that people in frail- care homes do not retain their dignity (83\%), and that such homes have a bad reputation (76\%). Hence $90 \%$ reported that they would not need the services of a frail-care home, nor were they ready for one $(95 \%)$. For them, a frail-care home is a place associated with death, as people go there to die (62\%), thus they would rather die than enter a frail-care home (55\%). In almost all these aspects Blacks felt more strongly than either whites or coloureds.

Retirement village managers, developers, housing providers and other role players, shared fairly similar perceptions amongst themselves. In general, they were of the opinion that elderly persons want to live with others of similar age $(69 \%)$ and are grateful that facilities are available where they can receive care $(75 \%)$, yet seldom feel ready to enter a frail-care home $(69 \%)$. This latter perception tends to hold, despite the fact that $50 \%$ stated that some individuals undoubtedly need the services of a frail-care home. Two thirds agreed that such homes have improved in recent years. Nevertheless, 53\% felt that frail-care homes are associated with death and 54\% that people in them do not retain their dignity. Rather disconcertingly, half of the housing providers and other role players predicted that, given increasing longevity, all elderly persons would end up in homes at some stage in the future, despite the fact that homes are reserved for frail persons only. They base this opinion on elderly persons' negative attitudes towards co-residence with children $(65 \%$ of the elderly respondents are against it), which contrasts with the government's view on who should provide housing for elderly persons.

\subsection{Perceptions of home-care services}

Home care includes the following types of services (whether in a housing facility or a private home): home cleaning; home nursing; meals-on-wheels; telephone reassurance; day-care programmes; special therapy programmes, e.g. support groups for those who suffer from Alzheimer's disease, strokes and arthritis; and life enrichment programmes (Loubser, 1993). These home services in both communities and retirement villages are under-developed in South Africa despite the fact that such service provision is directed at sustaining independent living in the community - which is in accordance with national policy on ageing. To establish a good home care programme, the participation of an elderly person's support system such as children, spouse, relatives and/or housekeeper, is of great importance. Geriatric institutions should place an emphasis on progammes to train people who render home care and to provide them with information on how to care for elderly clients.

Our research shows that $39 \%$ of all the elderly respondents indicated that they would use homecare services when they needed them. The percentage in the community sample was $35 \%$ and $43 \%$ in the retirement village sample. The lower percentage of community dwellers that responded affirmatively in this regard may be explained by lack of knowledge of most low income respondents of the concept of home care. 
The respondents in the retirement villages generally indicated (Table 2) that they wanted to live independently $(90 \%)$ but had made provision for access to frail-care services should they need them (84\%). They also emphasized that they did not want to live with their children (83\%), and $(70 \%)$ felt that they would not want to place any home care responsibilities on their children, which might jeopardize their relationship with the children (74\%). They would rather use facilities that render an equivalent service where they could also be surrounded by people of their own age $(65 \%)$. It was apparent that the respondents in the retirement villages would have sufficient funds to pay for such a facility when they needed it.

All the age groups and all the income groups are sure that they do not want to be a burden for some-one else, their children have a right to their independence, they want the security that they will be cared for although they are not ready for a home yet because it is the last resort. The middle to high income group belief that living with their children will jeopardise their relationship with their children $(71 \%$ and $70 \%)$ since home care will cause conflict within their child's family $(60 \%)$. Contrarily to this belief, the low income group (51\%) belief they have a right to live with their children. They also belief that they won't find anyone to share a home with (78\%). The 80+ age group $(63 \%)$ and the high income group (64\%) want to live with people of their own age. The young age group $(51 \%)$ as well as the low-income group (53\%) belief homes have bad reputations.

With regard to the cultural/race groups in the community sample, the research results show that the notion of home care was more acceptable to the black respondents than to the white ones (52\% vs $40 \%$ ). Black elderly respondents indicated (Table 2) that they would prefer to live with their relatives $(62 \%)$ and to be surrounded by people of different generations $(62 \%)$. They did not foresee a problem in being looked after by their family (76\%) and felt that home care would enable them to retain their dignity $(76 \%)$. The coloured and white respondents felt that it is not right to live with their children $(62 \%$ and $66 \%)$ because the latter's independence must be respected $(97 \%$ and $91 \%)$. Although they would not want their children to have to take care for them $(62 \%$ and $66 \%)$, they also felt that home care would enable them to retain their dignity $(71 \%$ and $56 \%$ ) which a frail-care unit would not do (40\% and 66\%).

Although the community-dwelling and retirement village respondents differed in opinion regarding their need for home care (45\% vs $21 \%)$, both samples agreed (Table 2 ) that they would not want to be a burden to anyone (94\% and $87 \%$ ) and wanted the security of knowing that they would be cared for $(93 \%$ and $84 \%)$.

\subsection{Sharing of home}

Although the role players belief that there are people that want to share their homes with other (66\%), the young aged between 60-70 years (28\%), the low income group (22\%), the cultural group respondents (blacks, 19\%; coloureds, 29\% and whites, 12\%) as well as the community$d$ welling respondents $(20 \%)$ are not sharing this view but belief that it won't be impossible to find some-one to share their homes. Only the white respondents belief that it will be too expensive to share.

\section{IMPLICATIONS OF THE FINDINGS FOR RETIREMENT HOUSING}

In the post-apartheid South Africa where public structures are being transformed, the provision of housing for the aged has become increasingly complex. The relevant government ministry has apparently abdicated their responsibilities in this regard. The private sector retirement housing industry therefore needs to fill a gap in the provision of such housing and to provide appropriate residential facilities for different market segments. 
First, the providers should note that the main criteria for the provision of retirement housing are linked to social-economic factors. These factors will determine the market segment which the providers will serve. Once the socio-economic profile of market segment has been determined, the providers may go a step further by tailoring housing and related care provision for the particular segment.

In the past, private sector providers only serviced the needs of the more affluent white elderly market (through the provision of retirement villages) and paid no attention to the less affluent market which offers market opportunities of its own. The developers directed all their efforts towards meeting the needs of this high-income sector, despite widespread concerns that they were predominantly profit-driven and were far less concerned with the needs of the broad market. It is appropriate that providers divert some of their efforts towards servicing other segments within the market and addressing the preferred qualities of related market segments.

The demand for retirement housing among elderly blacks and coloureds may be expected to increase, as socio-economic variables determine a market demand for independent living (e.g. in a retirement village). This pattern has been found in industrialised Asian countries like Japan, where multigenerational co-residence was previously the norm (Ferreira, 1998). The demand will also increase in South Africa once the effects of affirmative action change the per capita income of blacks and coloureds. Van den Berg (1998:11) states that "(I)n a few years the income distribution amongst the elderly may show a very different pattern as more and more blacks go into retirement with substantial private retirement provision, courtesy of the fundamental changes introduced in access to occupational retirement provision under pressure from the trade unions". This improvement in financial status will translate into a demand for better housing conditions and quality retirement housing. According to Ferreira (1998), evidence already exists in the Western Cape of a demand among elderly coloureds for units in retirement villages.

Developers and providers also need to pay attention to the image of retirement village facilities. The majority of the respondents in the community sample categorised retirement villages as either expensive facilities, which they could not afford and where they would not fit in, or as a frail-care facility. The most difficult image problem that all providers must combat is the misconception that there is only one form of retirement housing and that this is a frail-care facility. This perception was especially common among the low income respondents. Taking up residence in a frail-care home was perceived by these respondents to be "the worst thing that can happen to one". Providers thus need to improve the image of frail-care facilities through an improvement of the emotional and psychological environment of these facilities. Elderly consumers seek a caring environment where management and staff will treat them with respect and will allow them to maintain their dignity and privacy. Frail-care home residents have very little left in their lives and therefore these residents value their private belongings.

Both the community sample and the retirement village sample indicated that good communication between the residents and management of retirement facilities is very important $(81 \%$ and $66 \%$ respectively). This implies that residents want to interact with a staff that respects and understands them. Retirement housing managers need personnel who understand elderly adults' needs, respect their clients, and treat residents as individuals. This finding emphasises that the personnel of a retirement facility, from the domestic worker to the manager, should have unique qualities to understand the needs and preferences of the residents. Programmes to educate the personnel on meeting the needs of residents should be implemented. Examples of such programmes are how to communicate with an elderly person, how to have empathy and patience, how to develop greater awareness of the needs of the elderly, how to treat these special group of persons with respect and how to help elderly people to retain their dignity. This will enhance relationships between 
management and residents and improve the image of such facilities. Loubser (1993) has stated that if the management/ residents/community forces are not in harmony with one another, the symptoms of a "distressed retirement village syndrome" become apparent.

Developers and managers should also be concerned about the physical appearance of the facility. Residents want warm, light, comfortable surroundings with an air of vitality, not an institution that resembles a prison. Relocation from a family home is difficult enough for residents, without their having to give up their personal belongings. Rooms therefore need to be spacious. In addition to accommodating some of a resident's treasured possessions, a unit should enhance the resident's independence. Thus there needs to be a small kitchen attached to each unit where a resident can prepare light meals.

The fact that retirement village residents want their own kitchens (76\%) does not mean that they want to take all their meals in their unit. The majority will prefer to have breakfast in their unit but want a cooked meal for lunch provided by the facility.

In general, elderly consumers seek in-home care services as they want to maintain their independence for as long as possible. They do not want to rely on their children to assist them to maintain their independence. Care services should thus be marketed in terms of how utilisation of the services will prolong individuals' independent living. Elderly consumers are similar to anyone else in that they want all services to be available to them for when they might need them but they do not want to pay for them unless they actually use them. Providers should thus offer "à la carte" services.

Currently, retirement villages are aimed mainly at white middle to high income consumers. Housing providers should note that there is a growing need for rented units. Not all elderly persons have sufficient capital funds to buy a unit, whereas they may have sufficient cash flow to lease a unit. Retirement villages should thus provide a spectrum of financial options - of which renting a unit is one option. Very old persons would generally prefer to pay a monthly rental plus fees for services which they use.

What the respondents in the study were absolutely certain about was that they do not want to share their existing home with other people, as a means to enable them to continue to live in their home and thus to maintain their independence. (Persons with a low income frequently have little choice but to live with their children.) The respondents either felt that it would be too expensive to share their home $(50 \%)$, or that it would be impossible to find a person who was sufficiently caring to live with them $(55 \%)$.

Although $74 \%$ of the respondents indicated that they would prefer that a frail-care unit be attached to a retirement village, it will not always be possible for providers to accommodate such a preference. The reality is that the provision of frail-care facilities has become extremely expensive and few retirement villages can afford to operate these units. The retirement village industry will need to join hands to develop communal frail-care units, which are maintained by and serve multiple villages. This may not satisfy the preferences of all residents but will at least improve the long-term financial viability of villages which need to provide this service.

The over-development of frail-care facilities in the past resulted in several retirement villages experiencing financial problems, mainly because the amount of the village's monthly levy was insufficient for the facility to keep up with the expenses of maintaining a frail-care unit. Such units require a specialised labour force, which translates into a higher wage bill (Loubser, 1993). The "50-plus" retirement facility concept argues for the separate development of frail-care facilities, as a person at 50 years will have no need for such a facility, only for a safe environment. Thus frail- 
care facilities could either be developed at a later stage, or the village could link a unit that services multiple villages (Cluff, 1993).

According to the preferences of the respondents there is thus a need for retirement housing without frills. Not once did the respondents mention, for example, that residents regard club (sport and recreation) facilities as an important characteristic of a retirement facility, not even the respondents in the high-income category. Although the availability of recreation facilities within the village was important for the white (81\%) and coloured respondents (77\%) within the community sample, the social integration of residents in the broad community was also regarded as being important. Villages should thus rather aim to provide transport services to club facilities within the community, to enable the residents to be physically and socially active in this way, than to offer in-house club facilities. In addition, it should be noted that a majority of respondents regarded accessibility to outside services (in terms of the location of the village) as an important consideration. Apart form the 57\% rating for proximity to recreation opportunities, $65 \%$ and $69 \%$ respectively felt that closeness to shopping facilities and a hospital was important. It is therefore recommended that the providers of retirement village housing should avoid problems that stem from injudiciously developing complexes that through their inaccessibility isolate residents form the rest of the community.

As the main objective of the retirement village industry is to develop and provide housing, the developers and providers of such housing should aim to meet the needs and preferences of residents and prospective residents. However, at the same time the industry should bear in mind that the needs of these persons will change as they grow older, i.e. as they move from the "youngold" age group to the "old-old" and "very-old" age groups, and that their needs and expectations of facilities should be well planned and provided for.

\section{CONCLUSION}

It is therefore recommended that the providers of retirement village housing should avoid problems that stem from injudiciously developing complexes that through their inaccessibility isolate residents form the rest of the community. Retirement village developers and providers have an increasingly important role to play in the provision of housing and frail-care facilities and services for elderly people. The provision of housing for the middle to low income elderly categories should be seen as a challenge for the industry. To meet this challenge, the industry will have to adjust tot he specific needs, preferences and affordable levels of the various age, cultural and income groups amongst the non-frail elderly who are willing or able to live independently on their own or with family and friends. Developers should avail themselves of such new business opportunities and implement innovative and appropriate housing and care models accordingly.

\section{AKNOWLEDGEMENTS}

The first author would like to thank the Centre for Science Development and the University of Stellenbosch for financial support to conduct the research. Thanks also go to Prof. Monica Ferreira at the HSRC/UCT Centre for Gerontology for comments on earlier drafts of this article.

\section{REFERENCES}

ASSA2000 2003. AIDS and demographic model of the Actuarial Society of South Africa. 2000. Hyperlink [http://www.assa.org.za/downloads/aids/assa2000.asp]. 20 June 2003. 
FERREIRA, M. 1996. Personal communication. Cape Town.

FERREIRA, M. 1998. Personal communication. Cape Town.

FRONEMAN, C.A. 2004. Die rol van aftree-oorde in die behuisingsvoorsiening van bejaardes in Groter Kaapstad: 'n Stedelike Geografiese Perspektief. Stellenbosch: University of Stellenbosch. (Unpublished Doctoral thesis)

HOFMEYR, B.E.; MOSTERT, W.P. \& OOSTHUIZEN, J.S. 1997. Unpublished data. Pretoria: Human Sciences Research Council. With permission of the HSRC.

LOUBSER, H. 1993. The importance of developing the right facilities for the successful management of a retirement village. Proceedings of the AIC Conference, Johannesburg.

LUMPKIN, R., GIBLER, K.M. \& MOSCHIS, G.P. 1992. Retirement housing and long-term health care: attitudes and perceptions of the mature consumer. Lafayette, USA: AARP Andrus Foundation, University of Southwestern Louisiana.

SOUTH AFRICA, 1997. Department of Welfare and Population Development. White Paper on Social Welfare. Pretoria: Government Printer.

STATISTICS SOUTH AFRICA, 1996. Population Census. South Africa. Pretoria: Government Printers

STRYDOM, H. \& RIP, S. 1988. Die bejaarde in aftree-oorde in Pretoria: hul lewenstyl en persepsies. Pretoria: Human Sciences Research Council, Co-operative Research Programme on Ageing.

THE SOUTH AFRICAN PROPERTY OWNERS' ASSOCIATION (SAPOA). 1993. A Guide to Retirement Centre Development. Johannesburg. VEESA.

VAN DEN BERG, S. 1996. The means test for social assistance grants: Its application, fiscal risks and some recommendations. Paper prepared for the Department of Welfare and Population Development. Department of Economics: University of Stellenbosch.

VAN DEN BERG, S. 1998. Ageing, public finance and social security in South Africa. Southern African Journal of Gerontology, 7(1):3-9.

Dr CA Froneman, Mr MKR van Huyssteen and Prof IJ van der Merwe, Department of Geography and Environmental Studies, University of Stellenbosch, Stellenbosch, South Africa. 